Universidade Federal do Amazonas (Ufam). Manaus, Amazonas, Brasil. E-mail: <jlibardoni@ufam. edu.br >; <https://orcid. org/0000-0002-1048-8164>.

II Doutor em Ciências do Movimento Humano pela Universidade do Estado de Santa Catarina (Udesc). Florianópolis, Santa Catarina, Brasil.

III Universidade Federal do Amazonas (Ufam). Manaus Amazonas, Brasil. E-mail: <geyse_sadim@hotmail. com>; <https://orcid. org/0000-0002-9055-9857>.

IV Mestre em Educação pela Universidade Federal do Amazonas (Ufam). Manaus, Amazonas, Brasil.

v Universidade Federal de Santa Maria (UFSM). Santa Maria Rio Grande do Sul, Brasil. E-mail: <carlopsico4@ gmail.com>; <https://orcid org/0000-0003-1352-9141>

VI Doutor em Psicologia pela Universidade Federal do Rio Grande do Sul (UFRGS) Porto Alegre, Rio Grande do Sul, Brasil.

VII Universidade Federal do Amazonas (Ufam). Manaus, Amazonas, Brasil. E-mail: <profalmerinda@hotmail. com>; <https://orcid. org/0000-0002-4776-2155>.

vIII Doutora em Educação pela Universidade Federal do Rio Grande do Sul (UFRGS). Porto Alegre, Rio Grande do Sul, Brasil.

\section{$O$ atendimento educacional especializado para os educandos com autismo na rede municipal de Manaus-AM}

\author{
João Otacilio Libardoni dos Santos ${ }^{\mathrm{I}, \mathrm{II}}$ \\ Geyse Pattrizzia Teixeira Sadim ${ }^{\mathrm{III}, \mathrm{IV}}$ \\ Carlo Schmidt ${ }^{\mathrm{V}, \mathrm{VI}}$ \\ Maria Almerinda de Souza Matos ${ }^{\mathrm{VII}, \mathrm{VIII}}$
}

https://doi.org/10.24109/2176-6681.rbep.102.i260.4150

\section{Resumo}

Este artigo trata da síntese de resultados de pesquisa de mestrado em Educação, o qual objetivou caracterizar a organização e o funcionamento do atendimento educacional especializado (AEE), realizado nas salas de recursos multifuncionais (SRM), visando ao atendimento dos educandos com autismo na rede municipal de Manaus. Delineada pela abordagem qualitativa de caráter descritivo, a pesquisa foi norteada pelo método dialético. Como lócus da coleta de dados, foram escolhidas cinco escolas da rede municipal de Manaus que possuem SRM. Para a coleta de dados, foram utilizados roteiros de entrevistas semiestruturadas aplicadas aos professores participantes. Para análise das entrevistas, foi utilizada a análise de conteúdo de Bardin (1977). Os resultados e as discussões dos dados foram organizados de acordo com as categorias de análise definidas: encaminhamento; atividades desenvolvidas; perfil dos docentes que atuam no AEE; e parcerias. Constatou-se que os elementos problematizados neste estudo explicitam a compreensão de que o processo de inclusão, por meio 
do AEE, perpassa pelas políticas públicas de educação inclusiva e aponta que a organização e o funcionamento das SRM são fundamentais na construção de contextos inclusivos para os educandos com autismo.

Palavras-chave: atendimento educacional especializado; autismo; educação especial.

\section{Abstract \\ The special education service for students with autism in the municipal educational system of Manaus-AM}

This is a synthesis of the findings of a master's research in education. This research categorized the organization and operation of the special education service (atendimento educacional especializado - AEE), carried in multifunctional resources classrooms (salas de recursos multifuncionais SRM), which cared for students with Autism in the municipal educational system of Manaus. The research followed the dialectical method and used the descriptive qualitative approach. Five schools equipped with multifunctional resources classrooms within the municipal educational system of Manaus were chosen as a locus for data collection. The data itself was collected through semi-structured interviews applied to teachers participating in the research. Interviews were analyzed through Bardin's content analysis (1977). Results and discussions of data were organized according to the following categories of analysis: forwarding; developed activities; profile of the teachers working in the AEE; and partnerships. Findings revealed that the elements in this study explain the understanding that the inclusion process, through AEE, permeates inclusive educational public policies and indicates that the organization and operation of SRMS are key to develop inclusive contexts for students with autism.

Keywords: autism; special education; special educational services.

\section{Resumen \\ El servicio educativo especializado para estudiantes con autismo en la red municipal de Manaus-AM}

Este artículo aborda la síntesis de los resultados de la investigación del magíster en Educación, cuyo objetivo fue caracterizar la organización y el funcionamiento del Servicio Educativo Especializado (SEE), realizado en las Salas de Recursos Multifuncionales (SRM), con la finalidad de ayudar a los estudiantes con autismo en la red municipal de Manaus. Esbozado por el enfoque cualitativo de carácter descriptivo, la investigación se guio por el método dialéctico. Como lugar de recopilación de datos, se eligieron 
cinco escuelas de la red municipal de Manaus, que cuentan con salas de recursos multifuncionales. Para la recolección de datos, se aplicaron entrevistas semiestructuradas a los profesores participantes. Para el análisis de las entrevistas, se utilizó el análisis de contenido de Bardin (1977). Los resultados y las discusiones de los datos se organizaron de acuerdo con las categorías de análisis definidas: Encaminamiento; Actividades desarrolladas; Perfil de los docentes que trabajan en el SEE y Asociaciones. Se constató que los elementos problematizados en este estudio explican la comprensión de que el proceso de inclusión, por medio del SEE, impregna las políticas públicas de educación inclusiva y señala que la organización y el funcionamiento de las SRM son fundamentales en la construcción de contextos inclusivos para estudiantes con autismo.

Palabras clave: autismo; educación especial; servicio educativo especializado.

\section{Introdução}

Este artigo trata da síntese de resultados de pesquisa de mestrado em Educação ${ }^{1}$, o qual contou com o apoio da Fundação de Amparo à Pesquisa do Estado do Amazonas (Fapeam) e objetivou caracterizar a organização e o funcionamento do atendimento educacional especializado (AEE), realizado nas salas de recursos multifuncionais (SRM), visando ao atendimento dos educandos com autismo na rede municipal de Manaus.

A inclusão é hoje mais que uma proposta escolar, é uma proposta social. Passa pela luta por uma escola para todos, passa pela importância de educar para a pluralidade, para a convivência em uma sociedade diversificada, na qual o encontro das diferenças físicas, culturais, ideológicas, entre outras, é condição primeira para a transformação de toda uma sociedade (Matos, 2013). Marquezan (2012, p. 47) ressalta que "a Educação Inclusiva, tendo como pressuposto a 'Escola para todos', assegura igualdade de oportunidades, aceita a diversidade, trabalha na heterogeneidade". Reforça-se aqui a importância do espaço escolar inclusivo, em que todos os educandos convivam com as diferenças.

A sociedade moderna tem criado políticas e instrumentos legais com o objetivo de garantir condições e oportunidades igualitárias e democráticas. Percebidas como um processo de ampliação da circulação social, a inclusão promove a construção de uma sociedade que ofereça oportunidades variadas a todos os seus cidadãos e possibilidades criativas a todas as suas diferenças. Para Oliveira (2015, p. 91), o paradigma da inclusão legitima-se e difunde-se em nível mundial por meio das políticas educacionais, em que a sociedade e os sistemas de ensino são convocados a se reorganizarem conforme princípios democráticos para incluir a todos.

Com a perspectiva inclusiva, anseia-se que não somente os educandos com necessidades educacionais especiais participem plenamente do espaço 
escolar, mas que todos tenham as mesmas oportunidades; ainda que, para isso, sejam utilizados recursos e estratégias pedagógicas diferenciadas, ajustadas às suas necessidades individuais (Brasil. MEC, 2003).

Seguindo essa ótica, a inclusão escolar dos alunos com deficiência, transtornos globais do desenvolvimento e altas habilidades/superdotação, público-alvo da educação especial, vem sendo assegurada pelos instrumentos legais (Brasil, 1988; Brasil. MEC, 2008; Brasil. MEC. CNE. CEB, 2009; Brasil, 2011; Brasil, 2015) que orientam os sistemas de ensino para garantir a oferta do AEE como estratégia de inclusão, possibilitando que o aluno com necessidades educacionais especiais atinja os objetivos propostos para sua educação.

O AEE é compreendido no Decreto no 7.611/2011 (Brasil, 2011), em seu parágrafo $1^{\circ}$, como o conjunto de atividades, recursos de acessibilidade e pedagógicos, organizados institucional e continuamente, prestados de forma complementar à formação dos estudantes com deficiência e transtornos globais do desenvolvimento e de forma suplementar à formação de estudantes com altas habilidades ou superdotação. Conforme a legislação brasileira (Brasil. MEC, 2008; Brasil. MEC. CNE. CEB, 2009; Brasil, 2011), o AEE é ofertado em salas de recursos multifuncionais, as quais são ambientes dotados de equipamentos, mobiliários e materiais didáticos e pedagógicos para alunos com necessidades educacionais especiais no turno inverso da escolarização.

A norma que institui e estabelece "as Diretrizes Operacionais para o Atendimento Educacional Especializado na Educação Básica, modalidade Educação Especial" é a Resolução CNE/CEB no 4/2009 (Brasil. MEC. CNE. CEB, 2009). Em seu artigo $4^{\circ}$, define que o público-alvo do AEE é constituído pelos:

I - Alunos com deficiência: aqueles que têm impedimentos de longo prazo de natureza física, intelectual, mental ou sensorial.

II - Alunos com transtornos globais do desenvolvimento: aqueles que apresentam um quadro de alterações no desenvolvimento neuropsicomotor, comprometimento nas relações sociais, na comunicação ou estereotipias motoras. Incluem-se nessa definição alunos com autismo clássico, síndrome de Asperger, síndrome de Rett, transtorno desintegrativo da infância (psicoses) e transtornos invasivos sem outra especificação.

III - Alunos com altas habilidades/superdotação: aqueles que apresentam um potencial elevado e grande envolvimento com as áreas do conhecimento humano, isoladas ou combinadas: intelectual, liderança, psicomotora, artes e criatividade.

Os alunos com Transtornos Globais do Desenvolvimento (TGD) são definidos pela Política Nacional de Educação Especial na Perspectiva da Educação Inclusiva (Brasil, 2008) como aqueles que apresentam alterações qualitativas nas interações sociais recíprocas e na comunicação, um repertório de interesses e atividades restrito, estereotipado e repetitivo. Porém, o atual Manual Diagnóstico e Estatístico de Transtornos Mentais - 
DSM 5 (APA, 2014) faz referência ao autismo, denominando-o como Transtornos do Espectro Autista (TEA). Schmidt (2013, p. 13) define o TEA como um "distúrbio do desenvolvimento neurológico que deve estar presente desde a infância, apresentando déficit nas dimensões sociocomunicativa e comportamental".

A prevalência do TEA é de aproximadamente um caso para cada 59 crianças, de acordo com o Central for Diseases Control and Prevention (CDC, 2019). O autismo clássico afeta mais meninos do que meninas, em uma proporção de três a quatro meninos para cada menina. Segundo Schmidt (2017, p. 226), "o aumento dos casos de autismo tem sido consistentemente relatado ao longo dos últimos anos na literatura". Porém, ainda não se sabe se o aumento da prevalência nos últimos anos se deve a diferenças de metodologias empregadas ou a aumento real na frequência do transtorno (Brito; Vasconcelos, 2016).

O estudo de Santos e Elias (2018) caracterizou as matrículas dos estudantes com autismo nas cinco regiões do País. Os autores apontam que a região Norte, no que tange à concentração de matrículas de alunos com deficiência, permaneceu, com exceção do ano de 2009, em quarto lugar, seguida da região Centro-Oeste. O percentual de alunos com autismo na região Norte, em relação ao total de matrículas, subiu de 6,7\% (1.681 alunos) em 2010 para 13,1\% (9.833 alunos) em 2016.

Os educandos com autismo devem estar matriculados e participativos no AEE, de forma complementar, com vistas ao seu desenvolvimento global. Estudos de Costa (2015, 2014, 2012) e de Crochík (2015, 2011, 2003) revelam que as estratégias normativas, por si, não têm possibilitado a experiência entre alunos com e sem deficiência na escola pública. Assim, é preciso considerar que as leis, as convenções, as declarações e os decretos podem oferecer aportes e subsídios, mas a consciência crítica somente será possível se constituir nos espaços de formação oportunizados aos professores (Costa; Leme, 2016).

A literatura é farta em evidências sobre a defasagem dos alunos com autismo, especialmente quanto à aprendizagem relacionada à sua etapa de escolarização. Para que esses alunos de fato aprendam, é necessário que os recursos previstos por lei sejam atendidos na prática. Porém, a Lei $n^{\circ} 12.764 / 2012$ parece não ser suficiente para garantir o acesso e a permanência desses alunos, exigindo-se investigar como ocorre na região Norte do Brasil. Ademais, tendo em vista que o crescimento no número de matrículas dos alunos com TEA é superior ao número dos demais alunos com deficiência (Santos; Elias, 2018), constata-se a necessidade de levantar as seguintes questões: quais são as exigências de encaminhamento para que os educandos participem da sala de recursos multifuncionais? Quais as atividades desenvolvidas no atendimento educacional especializado para o educando com autismo? Qual o perfil dos docentes que atuam no atendimento educacional especializado? Há articulação entre o professor da sala de recursos multifuncionais e o professor da sala comum? 


\section{Metodologia}

Na busca da compreensão da realidade, com base no objetivo, na problematização do trabalho e se tratando de uma pesquisa voltada para a educação, este estudo teve como enfoque a abordagem qualitativa de caráter descritivo. O estudo qualitativo é o que se desenvolve em uma situação natural, é rico em dados descritivos, focalizando, de forma complexa e contextualizada, a realidade investigada (Lüdke; André, 2014).

Esta investigação foi norteada pelo método dialético, que penetra o mundo dos fenômenos, tendo em vista sua ação recíproca, a contradição inerente ao fenômeno e a mudança dialética (Marconi; Lakatos, 2011). Nesse sentido, o estudo se propôs a relacionar os pontos e os contrapontos existentes entre as legislações postas e a realidade encontrada nas SRM pesquisadas.

\section{Procedimentos e considerações éticas}

A Secretaria Municipal de Educação de Manaus (Semed) é constituída por 491 escolas, distribuídas em cinco zonas distritais, e apresenta 31 salas de recursos e 46 salas de recursos multifuncionais.

Como lócus da coleta de dados, foram sorteadas cinco escolas da área urbana, sendo uma de cada divisão distrital zonal (DDZ) da rede pública municipal de Manaus, as quais possuem SRM, o que apresenta uma amostragem aleatória simples: i) DDZ Sul; ii) DDZ Norte; iii) DDZ Oeste; iv) DDZ Leste I; v) DDZ Leste II. Participaram da pesquisa dez professores, sendo cinco da SRM e cinco da sala comum. Nas cinco SRM pesquisadas, estavam distribuídos 24 educandos com autismo, cada sala continha entre quatro e seis alunos.

Por envolver diretamente seres humanos, este estudo foi submetido ao Comitê de Ética em Pesquisa (CEP) da Universidade Federal do Amazonas (Ufam), por meio da Plataforma Brasil, obtendo a aprovação com o Certificado de Apresentação para Apreciação Ética (CAAE) $n^{\circ}:$ 88396318.5.0000.5020. Atende à Resolução $n^{\circ} 466 / 2012$ do Conselho Nacional de Saúde (Brasil. MS. CNS, 2012), que assegura o direito dos colaboradores da pesquisa, apresentando os princípios éticos tais como o Termo de Consentimento Livre e Esclarecido (TCLE).

\section{Instrumentos}

Para a coleta de dados, foi utilizado um roteiro de entrevista semiestruturada (elaborado pela pesquisadora), aplicado aos professores das SRM; e, para os professores das salas comuns, foi elaborada apenas uma questão. Isso posto, elegeu-se a entrevista semiestruturada por conta do diálogo que pode ser estabelecido entre a pesquisadora e os professores 
participantes da pesquisa, sobre as atividades desenvolvidas pela SRM e a articulação pedagógica entre os professores.

As questões para os professores das SRM foram elaboradas pela pesquisadora a partir das categorias de análise predefinidas: i) encaminhamento; ii) atividades desenvolvidas; iii) perfil dos docentes que atuam no AEE; iv) parceria. As perguntas foram construídas com base nas legislações e nos documentos norteadores da educação especial. Anteriormente, foi realizado um piloto para adequar o roteiro e a linguagem.

As entrevistas foram aplicadas pela pesquisadora responsável, nas salas de recursos multifuncionais das escolas, e duraram em média 1 hora. Depois de realizadas as entrevistas, o material foi organizado sistematicamente. As entrevistas foram gravadas em áudio, com autorização prévia dos participantes. Em seguida, foram transcritas para maior fidedignidade às falas apresentadas, com o auxílio do site oTranscribe.com.

\section{Análise de dados}

No processo de análise de dados, definido por Gil (2002, p. 133) como "uma sequência de atividades, que envolve a redução dos dados, a categorização desses dados, sua interpretação e a redação do relatório", os dados foram interpretados para, em seguida, serem contrastados com o referencial teórico, como as políticas públicas e a literatura nacional.

Para análise das entrevistas, foi utilizada a análise de conteúdo (Bardin, 1977), na qual as categorias podem ser criadas a priori ou a posteriori, isto é, com base apenas na teoria ou após a coleta de dados. Neste estudo, foi utilizada uma análise do tipo mista (a priori e a posteriori). A entrevista transcrita foi interpretada de acordo com as perguntas do questionário (categorias a priori), mas as subcategorias foram geradas a partir dos conteúdos das entrevistas (a posteriori). Para Bardin, a análise de conteúdo é organizada conforme ilustrado no Quadro 1.

\section{Quadro 1 - Categorias e subcategorias}

\begin{tabular}{|c|l|l|}
\multicolumn{1}{|c|}{ Categorias } & \multicolumn{1}{c|}{ Subcategorias } \\
\hline 1 & Encaminhamento & $\begin{array}{l}\text { Identificação } \\
\text { Laudo médico }\end{array}$ \\
\hline 2 & Atividades desenvolvidas & $\begin{array}{l}\text { Organização } \\
\text { Materiais didático/pedagógicos }\end{array}$ \\
\hline 3 & Perfil dos docentes que atuam no AEE & Formação inicial e continuada \\
\hline 4 & Parceria & Articulação pedagógica \\
\hline Fonte: Elaboração própria. &
\end{tabular}




\section{Resultados e discussões}

Os resultados e as discussões dos dados foram organizados de acordo com as categorias de análise definidas a priori, conforme os objetivos propostos e os marcos legais, a saber: encaminhamento; atividades desenvolvidas; perfil dos docentes que atuam no AEE; e parceria.

\section{Encaminhamento}

A identificação dos alunos que frequentam as SRM é um fator importante, pois está intrínseca a questões teóricas, como o papel do laudo, cuja necessidade para assegurar a matrícula no AEE é um ponto de grande controvérsia (Oliveira; Manzini, 2016). De acordo com os relatos dos professores, quando os pais sinalizam na hora da matrícula que o aluno é público da educação especial, o encaminhamento é feito de forma automática para o AEE. Quando não, depende da observação do professor da classe comum.

Porém, todos os professores alegaram que, independentemente de a criança já vir com algum laudo que a indique como público da educação especial, mesmo assim, ela é encaminhada para uma avaliação multidisciplinar no Complexo Municipal de Educação Especial (CMEE).

P1: O professor às vezes identifica, fica naquela suspeita e às vezes eu também, né? Porque a gente não tem como dar o diagnóstico. Aí, a gente pede ajuda para o CMEE. A gente encaminha esse aluno para lá, eles fazem a avaliação com a equipe multifuncional, aí vem a avaliação e o encaminhamento para sala de recursos.

Eu acho super importante que eles passem por lá, até porque aqui é o professor do ensino regular, eu e o pedagogo. E lá não, tem uma equipe melhor, especializada. E até venham com aquele resultado, a súmula, porque ali tem informações de como eu vou direcionar o meu trabalho.

P7: A gente conversa com os pais, e conforme for, ele é encaminhado para o CMEE para fazer a avaliação multifuncional.

P9: Sem essa súmula aqui, ele não pode participar da Sala.

Para o encaminhamento dos alunos, são seguidos alguns passos baseados nas legislações da Semed. Os estudantes público-alvo da educação especial, que necessitem ser identificados por serviços especializados,

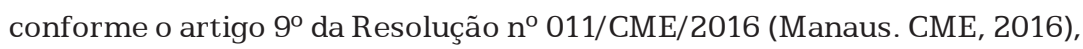
devem ser encaminhados pelas respectivas escolas, após prévia avaliação, realizada com orientação de equipe pedagógica e/ou multidisciplinar, fundamentada nos resultados obtidos pelos estudantes no processo de ensino e aprendizagem.

Nesse sentido, constata-se que, para o aluno chegar até a SRM e receber o atendimento especializado, não basta ser identificado como público da educação especial. É necessário seguir um protocolo, previsto na Resolução 
$\mathrm{n}^{\circ}$ 011/CME/2016 (Manaus. CME, 2016), com passos estipulados, desde o encaminhamento realizado pela professora regular, até o atendimento clínico, demonstrando, assim, a necessidade de algum parecer que indique a imposição da matrícula.

Um fator muito recorrente no encaminhamento desses alunos às SRM, é o laudo médico. No artigo 14 da Resolução nº 011/CME/2016 (Manaus. CME, 2016), o laudo médico é documento obrigatório para efeito de registro escolar e, consequentemente, para efeito da distribuição dos recursos do Fundo de Manutenção e Desenvolvimento da Educação Básica (Fundeb), recebendo pelo duplo cômputo das matrículas (Brasil, 2011).

A Nota Técnica nº 04/2014/MEC/Secadi (Brasil. MEC. SECADI. DPEE, 2014) estabelece que o laudo médico não pode ser exigido para garantir o direito à educação.

A exigência de diagnóstico clínico dos estudantes com deficiência, transtornos globais do desenvolvimento, altas habilidades/superdotação, para declará-lo, no Censo Escolar, público alvo da educação especial e, por conseguinte, garantir-lhes o atendimento de suas especificidades educacionais, denotaria imposição de barreiras ao seu acesso aos sistemas de ensino, configurando-se em discriminação e cerceamento de direito (Brasil. MEC. SECADI. DPEE, 2014).

Nesse caso, há uma contradição entre as determinações federais e municipais. E, seguindo essa linha indicada pela normativa da Semed, os professores, para executarem seu trabalho nas SRM, ficam à espera de um laudo ou parecer que justifique o atendimento educacional especializado.

P1: Quando é um aluno que não tem o laudo, aí eu não posso, não tenho autonomia para atender esse aluno. Eu tenho que encaminhar o aluno para o Complexo e só quando sai a avaliação, ele começa o atendimento. Quando esse aluno não tem o laudo, aqui nas recomendações eles sugerem que o aluno faça uma avaliação no neurologista.

P7: Depois que sai o laudo médico ou então sai a avaliação multiprofissional, a gente dá prosseguimento ao atendimento ou libera o aluno.

A solicitação de laudo clínico para encaminhamento de alunos que apresentem dificuldades educativas em seu processo de ensinoaprendizagem contribui para que esse alunado seja rotulado a partir de suas especificidades no processo educacional, não oferecendo subsídios para que professores possam desenvolver suas práticas pedagógicas adequadamente (Glat; Pletsch, 2011).

Dessa forma, verifica-se que o modelo clínico ainda é muito presente. A valorização do laudo médico leva os professores a acreditarem no fato de que as dificuldades para aprender são consequência de uma doença, fazendo girar o que Garrido (2009, p. 1) definiu como "uma grande engrenagem de encaminhamentos da escola a especialistas da área da saúde". 
O espaço e o tempo são "elementos pedagógicos importantes que precisam ser pensados e organizados para a participação ativa das crianças" (Serodio; Steinle, 2015, p. 131). A Resolução no 011/CME/2016 (Manaus. CME, 2016) indica, em seu parágrafo $1^{\circ}$, que o atendimento nas SRM poderá ser realizado de forma individual ou em pequenos grupos e em horário inverso ao frequentado no ensino comum.

Para viabilizar o funcionamento do AEE, o professor responsável deve estabelecer um cronograma de atendimento aos alunos. Os professores das SRM da rede municipal de Manaus atendem de segunda a quinta-feira; sexta-feira é dia de planejamento, conforme determinação da Secretaria. A orientação que eles recebem da Gerência de Educação Especial é que sejam grupos de no máximo cinco crianças, separados por níveis de aprendizagem e por deficiência. $\mathrm{O}$ atendimento acontece, na maioria dos casos, duas vezes na semana, uma hora por dia. Porém, o tempo de atendimento é um fator que implica a organização.

O estudo de Cardoso e Tartuci (2013), desenvolvido no município de Catalão, no estado de Goiás, apontou que o tempo disponível para o AEE também é um dos aspectos levantados pelas professoras em relação à organização do funcionamento das SRM e, em consequência disso, os critérios utilizados nas distribuições dos alunos em atendimentos em grupo e/ou individuais. Percebe-se, assim, que o funcionamento do AEE abrange a organização do tempo e do espaço físico, e fica a cargo do professor a responsabilidade em definir os critérios de atendimento.

Quanto às atividades desenvolvidas, os recursos de apoio são os elementos básicos das SRM. Assim, as atividades a serem desenvolvidas e os materiais e equipamentos a serem utilizados nos atendimentos devem estar descritos no plano de AEE do aluno. Segundo Sartoretto e Bersch (2010), os recursos pedagógicos podem ser considerados ajuda, apoio e, também, meios utilizados para alcançar um determinado objetivo; são ações, práticas educacionais ou material didático projetado para propiciar a participação autônoma do aluno com deficiência no seu percurso escolar. Os professores das SRM relataram que, dos materiais vindos do Ministério da Educação (MEC), o computador era o mais usado com as crianças autistas para execução de jogos.

P7: Olha, o (nome da criança) tem muita facilidade com o Paint, ele desenha extremamente bem. Ele gosta muito de Youtube também, eu uso o Youtube. Aí, outro aluno eu já uso alguns joguinhos que eu tenho no computador com ele, de alfabetização, ou então pesquisa, depende do aluno.

P9: Jogos que o MEC oferece, eu não utilizo. Porque não é legal. Eles lançam o pacote, pensam que aquilo ali é a realidade. Eu utilizo outros jogos a parte. Eu fui professor de informática em escola particular, então, facilitou ainda mais. Mas aqui, nós temos várias funções nesses computadores. Os autistas já entram na internet, mexem direitinho. 
Os jogos educacionais, sendo eles computacionais ou não, desenvolvem papel fundamental no processo de aprendizagem dos alunos, uma vez que são utilizados para auxiliá-los na criação de estratégias para a solução de problemas (Silva; Morais II, 2011).

Os professores também retratam a falta de manutenção e de atualização dos materiais recebidos.

P1: Eu estou até agora esperando eles virem instalar a impressora Braille, eu já tô mais de um ano com essa impressora aqui, já pedi várias vezes. Nós recebemos uma aluna cega esse ano. E a impressora tá parada e eu preciso que instale, porque a formação que eu fiz a gente vai perdendo se não praticar, aí demora que eu já não sei utilizar mais o recurso.

P5: Eu utilizava esse computador, mas ano passado deu um tilt e não ligou mais, eu já comuniquei, mas é assim. Eles disseram assim: "Tá queimada a fonte, mas nós vamos mandar o técnico". Aí veio uma equipe aqui, olhou o computador: "E a fonte, nós vamos trocar". Eu já falei com vários, inclusive da coordenação. Já foi informado para 3 assessores.

Nesse sentido, o programa de implantação de salas de recursos multifuncionais se propõe quanto à sua expansão, bem como novas ações a serem disponibilizadas às escolas com SRM, em efetivo funcionamento, como atualização, conversão, apoio complementar e visita técnica (Brasil. MEC. SEESP, 2010). Porém, os professores declaram que, desde a implementação das salas, não receberam novos materiais e nenhuma visita por técnico do MEC foi realizada. Desse modo, com os recursos limitados, os professores se dedicam à confecção de material.

Os professores utilizam recursos de baixo custo, como: papéis, papelão, tampinhas de garrafas, E.V.A. Com esses materiais, são construídos dominós, jogo da memória, caça-palavras, entre outros. A utilização de tecnologia assistiva de baixo custo vem se mostrando eficaz para indivíduos com limitações funcionais, auxiliando a superar as barreiras de mobilidade e comunicação, dessa forma, colaborando para o processo de inclusão escolar (Françani; Simões; Braccialli, 2009).

Assim, cabe salientar que as SRM são uma importante estratégia para o processo de inclusão escolar. Os recursos didáticos, pedagógicos e de acessibilidade que a compõem devem ser utilizados como ferramentas para a plena participação dos alunos público-alvo da educação especial, considerando suas necessidades específicas. Embora as SRM necessitem de atualização e manutenção, os professores buscam, com materiais de baixo custo, suprir esse déficit.

\section{Perfil dos docentes que atuam no atendimento educacional especializado}

A formação de professores para a educação especial tem sido alvo de preocupação. Tanto o processo de formação inicial quanto o de formação continuada são importantes, seja para o desenvolvimento profissional, seja 
para o processo de inclusão educacional, pois impactam a cultura escolar e influenciam nas tomadas de decisões pedagógicas (Anache et al., 2015). Nesse sentido, constitui-se como fundamental esclarecer quais exigências, em termos de formação, configuram a atuação do professor no AEE. Para isso, recorremos às orientações legais e políticas que permeiam a educação.

A Lei de Diretrizes e Bases da Educação Nacional (LDB) assegura, aos educandos com necessidades especiais, professores com especialização adequada em nível médio ou superior, para atendimento especializado, bem como professores do ensino regular capacitados para a integração desses educandos nas classes comuns (Brasil, 1996, art. 59, Inciso III).

Para atuar no AEE, definido no artigo 12 da Resolução CNE/CEB $n^{\circ} 4 / 2009$, "o professor deve ter formação inicial que o habilite para o exercício da docência e formação específica para a Educação Especial" (Brasil. MEC. CNE. CEB, 2009, p. 3).

A Resolução CNE/CEB nº 2/2001 (Brasil, 2001), que institui as diretrizes nacionais para a educação especial na educação básica, apresenta algumas definições quanto à formação dos professores especializados em seu artigo 18:

$\S 3^{\circ}$ Os professores especializados em educação especial deverão comprovar: (I) - formação em cursos de licenciatura em educação especial ou em uma de suas áreas, preferencialmente de modo concomitante e associado à licenciatura para educação infantil ou para os anos iniciais do ensino fundamental; (II) - complementação de estudos ou pós-graduação em áreas específicas da educação especial, posterior à licenciatura nas diferentes áreas de conhecimento, para atuação nos anos finais do ensino fundamental e no ensino médio;

$\S 4^{\circ}$ Aos professores que já estão exercendo o magistério devem ser oferecidas oportunidades de formação continuada, inclusive em nível de especialização, pelas instâncias educacionais da União, dos Estados, do Distrito Federal e dos Municípios (Brasil, 2001).

Está previsto pelas normativas legais o oferecimento de formação aos professores do AEE (Brasil, 2015; Manaus. CME, 2016). Porém, dos cinco professores pesquisados, dois não têm formação específica para atuar nas SRM, apenas um finalizou o curso específico de AEE e dois professores estão cursando.

Quando perguntados com que frequência a Secretaria promove cursos de atualização/formação, os docentes do AEE relatam que recebem poucas formações da Semed.

P1: Pena que as formações são muito rápidas e na maioria das vezes superficiais. A gente tem muita necessidade de formação, poderiam oferecer mais.

P3: Ano passado não tive nenhuma. Eu tive somente no início do ano, que teve dois dias de formação e durante o ano todinho não teve nenhuma formação.

P5: Normalmente, uma vez por ano. Às vezes, duas. Antigamente, tinham mais formações. Ano passado, eu achei poucas formações. 
O estudo de Silva, Tartuci e Deus (2015) também revela o contraponto de que, ao mesmo tempo em que o governo impõe a formação como critério para atuar, ele oferece subsídios insuficientes para que os professores se especializem.

É importante ficar claro que a inclusão não está apenas na teoria, ela deve estar nas salas de aula, e os alunos com deficiência estão lá para aprender. Não basta apenas falar que é uma escola inclusiva, a escola tem que ter condições de atendimento e os professores precisam estar preparados para atender as diversas demandas do processo de inclusão escolar (Oliveira et al., 2015). Aponta-se, assim, para a relevância da formação docente, tendo em vista a qualidade das práticas pedagógicas inclusivas.

\section{Parceria}

A Política Nacional de Educação Especial na Perspectiva da Educação Inclusiva (Brasil. MEC, 2008) propõe que, ao longo de todo o processo de escolarização, o AEE deve estar articulado com a proposta pedagógica do ensino comum. Os professores das SRM e das salas comuns (SC) relatam as dificuldades em manter a parceria.

P1 (SRM): Eu estou sempre conversando com eles, geralmente são conversas informais.

P2 (SC): Planejamento não, a gente não planeja junto. Mas ela me auxilia nas atividades que eu preciso.

P3 (SRM): Ano passado, eu tinha que vir a tarde para acompanhar. Só que como eu estava em outra escola, eu não tinha esse tempo. Como esse ano eu estou aqui o dia todo, apesar de eu estar em sala de aula também de manhã, mas pelo menos já tem uma possibilidade maior, quando a gente tá em ambiente comum, de eu observar o aluno.

P4 (SC): Eu confesso que eu até sinto falta, a gente não conversa. No planejamento, estava lendo sobre os nossos deveres: de planejar, de conversar. Eu senti falta, porque o meu contato com a pedagoga é mais direto, já com a professora da SRM eu já não tive tanto esse contato. Por exemplo, quando eu estava em sala de aula, ela estava na sala de recursos. Quando eu saía do intervalo, ela já não estava mais na escola.

P5 (SRM): Às vezes, uma ou outra procura alguma orientação. Algumas coisas a gente troca ideias.

P6 (SC): A gente não tem muito contato. São mais conversas informais.

P7 (SRM): A gente tem pouco contato com as professoras. Quando chega algum aluno, eu forneço material, eu explico um pouco, não dá para explicar muita coisa, porque é todo tempo correndo.

P8 (SC): É difícil a gente entrar em contato. Tenho mais com os pais.

P9 (SRM): Dia de sexta-feira, eu tenho que visitar as escolas dos meus alunos da sala de recursos, dos que não são daqui. Os daqui eu já tenho relação todos os dias, não preciso. Só que eu nem vou, porque eu ligo para eles. Os pais que vão lá, dão a folhinha do relatório, eles fazem e enviam para mim. Sem eu ir lá na escola.

P10 (SC): A gente conversa, porque tem coisas que só o professor da sala de recursos consegue realizar. 
Ao cruzar as repostas de todos os professores, constata-se que o contato entre eles é muito pequeno, a maioria se reduz a conversas informais. Não há, de fato, parceria para um trabalho em conjunto entre os dois professores.

Além da interlocução com os professores da própria escola, a maior dificuldade, segundo eles, está em manter parceria com os professores daqueles alunos pertencentes às outras escolas. No estudo de Oliveira (2015), também se encontram presentes, entre os depoimentos, docentes que relatam suas dificuldades para atuar junto às demais escolas com os professores das salas comuns.

Turchiello, Silva e Gareschi (2014) nos dizem que é importante que o AEE seja oferecido na própria escola, sempre que possível, pois essa oferta possibilita maior interlocução entre o professor do AEE e os do ensino comum. Essa proximidade beneficia o processo de aprendizagem do aluno, pois o professor do AEE poderá acompanhar ativamente a escolarização desse sujeito, bem como os recursos pedagógicos e de acessibilidade utilizados. Além disso, esse profissional poderá atuar, de forma mais efetiva, junto ao professor do ensino comum, oferecendo suporte necessário ao ensino do aluno.

Alves (2006, p. 17) nos relembra que o professor da SRM tem como uma de suas funções a atuação, de forma colaborativa, com o professor da classe comum para a definição de estratégias pedagógicas que favoreçam o acesso do aluno com necessidades educacionais especiais ao currículo e a sua interação no grupo. Essa atribuição é confirmada na Resolução CNE/ CEB n ${ }^{\circ}$ 4/2009:

Estabelecer articulação com os professores da sala de aula comum, visando à disponibilização dos serviços, dos recursos pedagógicos e de acessibilidade e das estratégias que promovem a participação dos alunos nas atividades escolares (Brasil. MEC. CNE. CEB, 2009, Art. 13, Inciso VIII).

Conforme Capellini e Mendes (2007), a literatura estrangeira vem apontando que a colaboração entre professores da educação comum e da especial tem permitido uma reflexão da prática pedagógica e ampliado as possibilidades de melhor atender alunos com deficiência na classe comum, além de proporcionar um desenvolvimento profissional centrado na própria escola.

Sabemos que as frentes de trabalho de cada profissional são distintas, mas estes precisam interagir para que seus objetivos específicos de ensino sejam alcançados, realizando um trabalho interdisciplinar e colaborativo (Cesarin; Trevisan, 2017, p. 24).

A colaboração entre o professor da educação regular e o do ensino especial é um dos modelos de trabalho colaborativo que vem sendo investigado. O ensino colaborativo tem sido utilizado para favorecer a inclusão escolar, envolvendo a parceria direta entre os professores da educação comum e da especial (Machado; Almeida, 2010). 
Ao fazer menção à atuação pedagógica com caráter colaborativo, a proposta do AEE apresenta-se como uma ação que possibilita resultados mais imediatos, porque funciona simultaneamente aos fatos ocorridos, possibilitando uma interação mais rápida entre os docentes para a intervenção pedagógica necessária (Braun; Marin, 2016).

Assim, para que o AEE consiga atender à demanda dos alunos da educação especial, é preciso que o professor que atua nas SRM estabeleça comunicação com o professor da sala comum, a fim de obter informações sobre o atendimento ou o retorno das atividades desenvolvidas. Somente por meio dessa parceria e desse trabalho colaborativo os professores poderão desenvolver um planejamento efetivo de acordo com as necessidades de cada aluno.

\section{Considerações finais}

Pautando nosso caminho nas políticas públicas de educação inclusiva, a partir do cenário da educação especial e do Brasil frente à Política Educacional Inclusiva, discorremos sobre o funcionamento das salas de recursos multifuncionais na construção de contextos inclusivos para o atendimento educacional especializado aos educandos com autismo. Sendo assim, com base nos resultados desta pesquisa, podemos constatar alguns aspectos.

A solicitação de laudo clínico ainda é presente no sistema educacional, havendo uma contradição entre a legislação nacional e a municipal.

Os critérios de atendimento e organização ficam a cargo do professor. Com relação aos materiais, o uso do computador para execução de jogos foi o mais citado pelos professores. A fala dos professores também retrata a falta de manutenção e atualização dos materiais recebidos. Assim, a utilização de tecnologia assistiva de baixo custo é um meio para suprir essa carência de recursos.

Apesar de a oferta de formação aos professores estar prevista nos textos legais, dos cinco professores pesquisados, dois deles não têm formação específica para atuar nas SRM, apenas um finalizou o curso específico de AEE e dois professores estão cursando.

Quanto às parcerias, os professores das SRM relatam como acontece e quais as dificuldades em manter a articulação pedagógica com os professores das salas comuns. Os professores das classes comuns também reafirmam essa lacuna na parceria, reduzida somente a conversas informais.

Os elementos problematizados neste estudo explicitam compreensões de que o processo de inclusão, por meio do AEE, perpassa pela organização e pelo funcionamento das SRM, revelando, entretanto, que, mesmo após dez anos da Política Nacional de Educação Especial na Perspectiva da Educação Inclusiva (Brasil, 2008), esse atendimento ainda enfrenta muitas dificuldades.

Apesar dos avanços legais e da expansão de pesquisas na área da educação especial, garantir a efetivação de uma política de inclusão com 
uma educação de qualidade para todos, inclusive aos alunos com autismo, depende de ações eficientes do sistema de ensino e pressupõe vencer inúmeros desafios.

Para a modificação da atual realidade das escolas da rede municipal de Manaus, seria interessante tomar como foco a formação de professores, com base no trabalho colaborativo e na reorganização do espaço-tempo do AEE. Além disso, a legislação municipal deve ser adequada à federal quanto à exigência de laudo médico, visto que a sua obrigatoriedade denota imposição de barreiras, configurando-se em discriminação e cerceamento de direito.

Para que a inclusão escolar, além do educando com autismo, se realize de fato, é necessário esforço coletivo, de modo que o sistema de ensino, a escola, desde a gestão, os professores, a família e os estudiosos se envolvam e acreditem nesse processo. Acreditar no potencial humano é uma bandeira dos direitos humanos, levando em conta o sujeito global, e não somente a sua deficiência.

Os sistemas de ensino devem se propor a conhecer seus profissionais, sua formação acadêmica e específica, quais suas concepções de ensino e suas reflexões a respeito do processo de ensino e aprendizagem. Assim, torna-se condição importante para o pleno desenvolvimento da inclusão escolar a garantia de uma política efetiva de formação docente, tanto inicial quanto continuada, a todos os professores que atuam no AEE e que atendam às necessidades educacionais dos alunos conforme proposto nos textos legais.

É importante também destacar que um dos pontos frágeis desta pesquisa é que, apesar de a amostra ser representativa, o número total de professores ouvidos ainda é pequeno, podendo não representar a totalidade regional.

\section{Agradecimentos}

O presente trabalho foi realizado com apoio da Coordenação de Aperfeiçoamento de Pessoal de Nível Superior - Brasil (Capes) - Código de Financiamento 001.

\section{Referências}

ALVES, D. O. Sala de recursos multifuncionais: espaços para atendimento educacional especializado. Brasília: MEC, SEESP, 2006.

AMERICAN PSYCHIATRIC ASSOCIATION (APA). Manual diagnóstico e estatístico de transtornos mentais: DSM-5. 5. ed. Porto Alegre: Artmed, 2014.

ANACHE, A. A. et al. Formação de professores para o atendimento educacional especializado nas salas de recursos multifuncionais do 
estado de Mato Grosso do Sul. In: MENDES, E. G.; CIA, F.; CABRAL, L. S. A. (Orgs.). Inclusão escolar e os desafios para a formação de professores em Educação Especial. São Carlos: Marquezine \& Manzini; Bauru: ABPEE, 2015.

BARDIN, L. Análise de conteúdo. Lisboa: Edições 70, 1977.

BRASIL. Constituição (1988). Constituição da República Federativa do Brasil. Brasília, DF: Câmara dos Deputados, 1988.

BRASIL. Lei n ${ }^{\circ}$ 9.394, de 20 de dezembro de 1996. Estabelece as diretrizes e bases da educação nacional. Diário Oficial da União, Brasília, DF, 23 dez. 1996. Seção 1, p. 1.

BRASIL. Decreto n ${ }^{0} 7.611$, de 17 de novembro de 2011. Dispõe sobre a educação especial, o atendimento educacional especializado e dá outras providências. Diário Oficial da União, Brasília, DF, 18 nov. 2011. Seção 1, p. 12.

BRASIL. Lei no 13.146, de 6 de julho de 2015. Institui a Lei Brasileira de Inclusão da Pessoa com Deficiência (Estatuto da Pessoa com Deficiência). Diário Oficial da União, Brasília, DF, 7 jul. 2015. Seção 1, p. 2.

BRASIL. Ministério da Educação (MEC). Estratégias para a educação de alunos com necessidades educacionais especiais. Brasília, DF: MEC/ Seesp, 2003.

BRASIL. Ministério da Educação (MEC). Política Nacional de Educação Especial na perspectiva da educação inclusiva. Brasília, DF: MEC, 2008.

BRASIL. Ministério da Educação (MEC). Conselho Nacional de Educação (CNE). Câmara de Educação Básica (CEB). Resolução no 2, de 11 de setembro de 2001. Institui Diretrizes Nacionais para a Educação Especial na Educação Básica. Brasília, DF, 2001.

BRASIL. Ministério da Educação (MEC). Conselho Nacional de Educação (CNE). Câmara de Educação Básica (CEB). Resolução no 4, de 2 de outubro de 2009. Institui Diretrizes Operacionais para o atendimento educacional especializado na educação básica, modalidade educação especial. Diário Oficial da União, Brasília, DF, 05 out. 2009. Seção1, p. 17.

BRASIL. Ministério da Educação (MEC). Secretaria de Educação Continuada, Alfabetização, Diversidade e Inclusão (Secadi). Diretoria de Políticas de Educação Especial (DPEE). Nota Técnica $n^{\circ}$ 04, de 23 de janeiro de 2014. Orientação quanto a documentos comprobatórios de alunos com deficiência, transtornos globais do desenvolvimento e altas habilidades/superdotação no Censo Escolar. Brasília, DF, 23 jan. 2014. 
BRASIL. Ministério da Educação (MEC). Secretaria de Educação Especial (Seesp). Manual de orientação: programa de implementação de salas de recursos multifuncionais. Brasília, DF: MEC, Seesp, 2010.

BRASIL. Ministério da Saúde (MS). Conselho Nacional de Saúde (CNS). Resolução no 466, de 12 de dezembro de 2012. Diário Oficial da União, Brasília, DF, 13 jun. 2013. Seção 1, p. 59.

BRAUN, P.; MARIN, M. Ensino colaborativo: uma possibilidade do atendimento educacional especializado. Revista Linhas. Florianópolis, v. 17, n. 35, p. 193-215, set./dez. 2016.

BRITO, A. R.; VASCONCELOS, M. M. de. Transtornos do espectro autista. In: MAIA, H. (Org.). Necessidades educacionais especiais. 2. ed. Rio de Janeiro: Wak Editora, 2016. (Coleção Neuroeducação, 3).

CAPELLINI, V. L. M. F.; MENDES, E. G. O ensino colaborativo favorecendo o desenvolvimento profissional para a Inclusão Escolar. Educere et Educare Revista de Educação, Cascavel, PR, v. 2, n. 4, p. 113-128, jul./dez. 2007.

CARDOSO, C. R.; TARTUCI, D. O funcionamento do atendimento educacional especializado nas salas de recursos multifuncionais e a atuação docente. In: CONGRESSO BRASILEIRO MULTIDISCIPLINAR DE EDUCAÇÃO ESPECIAL, 7.; ENCONTRO DA ASSOCIAÇÃO BRASILEIRA DE PESQUISADORES EM EDUCAÇÃO ESPECIAL, 8., 2013, Londrina. Anais... Londrina: UEL, 2013. p. 3307-3320.

CENTRAL FOR DISEASES CONTROL AND PREVENTION (CDC). Dados e estatística sobre transtorno do espectro do autismo. 2019. Disponível em: $<$ https://www.cdc.gov/ncbddd/autism/data.html>. Acesso em $12 \mathrm{dez}$. 2019 .

CESARIN, M. M.; TREVISAN, P. F. F. O atendimento educacional especializado (AEE): ações para incluir. In: PAVÃO, A. C. O.; PAVÃO, S. M. O. (Org.). Atendimento educacional especializado: estado da arte. Santa Maria, SC: UFSM, 2017.

COSTA, V. A. Formação de professores e educação inclusiva. In: CARVALHO. M. B. W. B.; COSTA, V. A.; MIRANDA, T. G. (Org.). Educação básica, educação superior e inclusão escolar: pesquisas, experiências e reflexões. Niterói: Intertexto, 2012. p. 23-34.

COSTA, V. A. Educação inclusiva, teoria e produção do conhecimento: desafios à arte da práxis docente. In: MENDES, E. G.; CIA, F. (Org.). Inclusão escolar e o atendimento educacional. São Carlos: Marquezine \& Manzini; ABPEE, 2014. p. 29-39. 
COSTA, V. A. Educação e formação: inclusão na escola pública. Revista Entreideias. Salvador, v. 4, n.1, p. 51-70, jan./jun. 2015.

COSTA, V. A.; LEME, E. S. Educação inclusiva no Brasil: aspectos políticos, sociais e humanos. In: COSTA, V. A.; SEGURA, R. V. (Org.). Educação inclusiva na América Latina: políticas, pesquisas e experiências. Niterói: Intertexto, 2016, p.21-41.

CROCHÍK, J. L. Atitudes a respeito da educação inclusiva. Revista Movimento. Niterói, n. 7, p. 19-38, maio 2003.

CROCHÍK, J. L. (Coord.). Preconceito e educação inclusiva. Brasília, DF: Secretaria dos Direitos Humanos, 2011.

CROCHÍK, J. L. Educação inclusiva, subjetividade, preconceito e direitos humanos: qual sua relação?. In: SILVA, A. M.; COSTA, V. A. (Org.). Educação inclusiva e direitos humanos: perspectivas contemporâneas. São Paulo: Cortez, 2015. p. 23-53.

FRANÇANI, C. O.; SIMÕES, E. M.; BRACCIALLI, L. M. P. Tecnologia assistiva: desenvolvimento de recursos de baixo custo. Revista Ciência em Extensão, São Paulo, v. 5, n. 2, p. 108, 2009.

GARRIDO, J. Questionando a medicalização de crianças com dificuldade de escolarização: o estado da arte da produção acadêmica sobre o tema nas áreas de educação, medicina e psicologia. In: REUNIÃO ANUAL DA ANPED, 32., 2009, Caxambu. Anais...Caxambu: ANPEd, 2009. p. 1-6.

GIL, A. C. Como elaborar projetos de pesquisa. 4. ed. São Paulo: Atlas, 2002.

GLAT, R.; PLETSCH, M. D. Estratégias educacionais diferenciadas para alunos com necessidades especiais. Rio de Janeiro: EdUERJ, 2011.

GRANDO, R. C. O jogo na educação: aspectos didático-metodológicos do jogo na educação matemática. São Paulo: Unicamp, 2001.

MARCONI, M. A; LAKATOS, E. M. Metodologia científica. 6. ed. São Paulo: Atlas, 2011.

LAZZERI, C. Educação inclusiva para alunos com autismo e psicose: das políticas educacionais ao sistema de ensino. 2010. 111f. Dissertação (Mestrado em Educação) - Universidade Federal de Santa Maria, Rio Grande do Sul, 2010.

LÜDKE, M.; ANDRÉ, M. E. D. Pesquisa em educação: abordagens qualitativas. 2. ed. Rio de Janeiro: E.P.U., 2014. 
MACHADO, A. C.; ALMEIDA, M. A. Parceria no contexto escolar: uma experiência de ensino colaborativo para a educação inclusiva. Revista Psicopedagogia, São Paulo, v. 27, n. 84, p. 344-351, 2010.

MANAUS. Conselho Municipal de Educação do Município de Manaus (CME). Resolução n. 011/CME/2016. Institui novos procedimentos e orientações para educação especial na perspectiva da educação inclusiva, no Sistema Municipal de Ensino de Manaus. Diário Oficial do Município de Manaus. Manaus, 13 jun. 2016, v. 17. n. 3929.

MARQUEZAN, R. A Educação inclusiva no paradigma emergente. In: MATOS, M. A. de S. (Org.). Educação especial, políticas públicas e inclusão: desafios da prática e contribuições da pesquisa no NEPPD/ FACED/UFAM. Manaus: Vitória, 2012.

MATOS, M. A. S. Cidadania, diversidade e educação inclusiva: um diálogo entre a teoria e a prática na escola pública. Manaus: Edua, 2013.

OLIVEIRA, C. C. B.; MANZINI, E. J. Encaminhamento e perfil do públicoalvo da educação especial de uma sala de recursos multifuncionais: estudo de caso. Revista Brasileira de Educação Especial, Marília, v. 22, n. 4, p. 559-576, out./dez. 2016.

OLIVEIRA, I. A. et al. A formação dos professores de salas de recursos multifuncionais de escolas da Rede Municipal de Belém. In: MENDES, E. G.; CIA, F.; CABRAL, L. S. A. (Org.). Inclusão escolar e os desafios para a formação de professores em Educação Especial. São Carlos, SP: Marquezine \& Manzini: ABPEE, 2015.

OLIVEIRA, R. M. G. Inclusão escolar: articulação entre sala de ensino regular e atendimento educacional especializado no município de Imperatriz, MA. In: COSTA, V. A. (Org.). Formação e pesquisa: articulação na educação inclusiva. Niterói: Intertexto, 2015.

SANTOS, V.; ELIAS, N. C. Caracterização das matrículas dos alunos com transtorno do espectro do autismo por regiões brasileiras. Revista Brasileira de Educação Especial. Marília, v. 24, n. 4, p. 465-482, out./ dez. 2018.

SARTORETTO, M. L.; BERSCH, R. C. R. A educação especial na perspectiva da inclusão escolar: recursos pedagógicos e comunicação aumentativa e alternativa. Brasília, DF: MEC, Seesp; Fortaleza: UFC, 2010 .

SCHMIDT, C. Autismo, educação e transdisciplinaridade. Campinas, SP: Papirus, 2013. 
SCHMIDT, C. Transtorno do espectro autista: onde estamos e para onde vamos. Psicologia em Estudo, Maringá, v. 22, n. 2, p. 221-230, abr./jun. 2017.

SERODIO, S. C. F.; STEINLE, M. C. B. A importância da organização do espaço para atender o aluno do $1^{\circ}$ ano do ensino fundamental de nove anos. In: SEMANA DA EDUCAÇÃO, 16.; SIMPÓSIO DE PESQUISA E POS-GRADUAÇÃO EM EDUCAÇÃO, 6., 2015. Londrina. Anais... Londrina: UEL, 2015. p. 127-142.

SILVA, I. K. O.; MORAIS II, M. J. O. Desenvolvimento de jogos educacionais no apoio do processo de ensino-aprendizagem no ensino fundamental. Revista Holos, Natal, v. 5, ano 27, p. 153-164, out./dez. 2011.

SILVA, M. R.; TARTUCI, D.; DEUS, D. C. M. A formação dos professores de atendimento educacional especializado de Goiás e a ressignificação de saberes docentes. In: MENDES, E. G.; CIA, F.; CABRAL, L. S. A. (Orgs.). Inclusão escolar e os desafios para a formação de professores em educação especial. São Carlos: Marquezine \& Manzini: ABPEE, 2015.

TRIVIÑOS, A. N. S. Introdução à pesquisa em ciências sociais: a pesquisa qualitativa em educação. São Paulo: Atlas, 1987.

TURCHIELLO, P.; SILVA, S. S. M.; GARESCHI, T. Atendimento educacional especializado. In: SILUK, C. P. (Org.). Atendimento educacional especializado: contribuições para a prática pedagógica. Santa Maria, RS: UFSM, 2014.

Recebido em 12 de fevereiro de 2020.

Aprovado em 15 de dezembro de 2020. 